\title{
中国大地构造宏观格架及其与矿产资源的关系 根据地球物理资料的认识
}

\author{
刘光鼎 郝天珧 刘伊克 \\ (中国科学院地球物理研究所, 北京 100101)
}

\section{关链词大地构造 宏观格架 地球物理}

大地构造及其演化是地质学的理论基础, 也是地球科学中对地球的结构、成分、运动和历 史进行考察所取得的规律性总结, 从而, 它对于生产实践活动也具有重要的意义.

地质学家长期对岩石露头反复进行细致的观测, 编绘出各种比例尺的地质图件, 而根据不 同时代的构造运动及其作用的认识与判断所编制的大地构造图件, 则是从理论上对各种地质 现象做出规律性的概括, 进而为找矿勘探服务,也是环境保护和灾害防治的参考.

地球物理应用重力、磁力、电磁、地震、地热和放射性等物理学的方法与技术来研究地球, 针对某些目标任务对地球进行测量, 可以提供地球内部结构与状态的基本数据. 例如, 位场与 波动的层析成像能够给出地下的三维速度结构. 地球化学从元素成分出发, 对地层岩石的组 分进行测定与分析, 为研究地球提出另一条探索途径. 这些新学科开拓并深化了关于地球研 究的理论与实践, 不仅极大地丰富了研究的内容, 而且提供了广泛的资料. 因此当前地球科学 要求对地质、地球物理、地球化学及其他有关学科作高层次的综合研究, 以求得对地球作出比 较全面的认识. 对于基础理论研究如此, 对于解决国民经济建设中涌现出的大量实际问题更 是如此.

但是, 任何具体研究都必须在宏观认识的指导之下进行. 中国大地构造格架的研究具有 宏观总体的性质, 既应在前人工作的基础上深化、升华并包容地质、地球物理等多方面的最新 研究成果, 又应作为工作假说或解决问题的初始条件, 接受实践检验, 并作为深化认识的基础.

\section{1 地质认识}

中国大陆位于欧亚板块之上. 在长期地质演化的历程中它由多个块体拼合而成, 并受到 印度板块和太平洋板块的作用而呈现出复杂多样性并带来了众多的困惑. 许多先驱者, 尤其 是地质家通过大量的实际观测, 提出了对中国大地构造的认识与观点, 作出了卓越的贡献. 例 如, 李四光指出: 中国的地势, 从青藏高原逐级向太平洋降低, 并在前震旦纪变质基底的基础 上, 论述了以后各期的造山运动, 指出阴山、秦岭和南岭东西褶皱带与华夏构造相干扰 ${ }^{[1]}$; 黄 汲清从多旋回观点出发, 探讨了中国大地构造的基本轮廓, 并划分出特提斯域和滨太平洋 域 ${ }^{[2]}$, 而张文佑则注意并集中探讨了中国断裂构造体系 ${ }^{[3]}$, 等等.

1969 年开始, 地球科学的发展取得了新的进展, 一批年轻的科学家在系统地总结大洋地 球物理资料的基础上提出岩石层板块大地构造, 并以离散(洋脊裂谷)、聚玫(海沟-岛弧-弧后 盆地)与剪切(转换断层)三种边界, 将地球表面岩石层划分为 6 大板块和若干小板块, 并指出 
其运动模式有如传送带. 这样, 岩石层板块构造就继承并发展了本世纪初期的大陆漂移 (A. Weggener, 1915)、中期的海底扩张 (H. H. Hess, 1951)理论, 而成为以活动论为基本内涵的新 地球观.

此后, 1981 年, 李春煜对亚洲大陆的地质情况进行总结并编绘出亚洲大地构造图 ${ }^{[4]}$. 1982 年, 王鸿祯将中国地壳历史发展划分为陆核形成、地台形成、联合大陆形成及其解体等四 大阶段 ${ }^{[5]} ; 1989$ 年, 朱夏在研究中国海时指出, 中国大陆是由多个块体 (Block) 拼合而成的. 它经历了 5 幕演化史, 其中印支期以前为古全球构造阶段, 包括前寒武纪陆核形成并向克拉通 发展和古生代期间块体拼合, 海水退出, 呈现中国大陆雉形; 印支以后, 为新全球构造阶段, 在 板块构造体制下, 中国大陆经历晚印支-早燕山 $\left(\mathrm{T}_{3}-\mathrm{K}_{1}\right)$ 时期的严重挤压改造, 晚燕山-早喜山 $\left(\mathrm{K}_{2}-\mathrm{E}_{2}^{3}\right)$ 时期的板缘聚玫, 板内拉张, 形成众多陆相沉积盆地, 以及晚渐新世以来 $\left(\mathrm{E}_{3}^{3}-\mathrm{Q}\right)$ 板缘 俯冲而板内沉降 ${ }^{[6]}$. 朱夏十分重视块体之间结合带的研究, 他认为随着块体之间的相对运 动, 中国大陆构造有如一盘麻将, 其中 “开” 即开局, 是块体的分裂或离散; “吃”, 即块体间的闭 合或聚敛, 一个块体俯冲于另一个块体之下; “碰”, 即两个块体在不同的运动方向上相碰撞而 形成低缓山系; “扛”, 即两个块体相对碰撞出现陡峭山带; “花”, 即两个块体相对俯冲, 造成花 式构造 ${ }^{[7]}$.

\section{2 地球物理场含义}

地球物理的重要能力在于了解并提供地下三维结构及相应物性参数, 我们希望由此对大 地构造加深认识.

应用物理学的理论和方法技术对岩石层进行观测, 采集数据, 获取地球物理场的信息称为 正演问题. 对地球物理场进行定性或定量的解释, 求得对地下结构与岩石物性的认识, 称之为 反演问题. 从数学上看, 地球物理场的反演问题是多解的, 即并不存在唯一的解答. 但是, 求 解地球物理场反演问题又是认识岩石层结构及演化过程的重要途径. 因此, 只有努力增加约 束条件,通过多种地球物理场的综合研究来建立地质认识.

中国航磁异常图虽然在华北、扬子、南华等块体的结合带上有所反映, 但众多局部正负异 常的表现说明它受浅层岩体的严重干扰, 经过化极之后的延拓可以给出断裂延展的走向, 而根 据磁异常计算出来的居里面的深度展布, 可以排除部分浅层干扰, 更好地反映出块体之间的结 合带, 包括航磁发现的郯庐深大断裂. 问题是居里面究竟具有怎样的地质意义? 过去, 从物理 上看, 居里温度是岩石磁性消失的界限, 从而认为居里面是一个等温面, 同时也是磁测能达到 的最大深度. 即使如此, 也难于赋于居里面以任何地质意义. 更何况近年一些超深钻的报告 指出, 在居里面下仍有磁性地层存在; 而如果地球磁场果真是核幔边界或外核附近磁流体发电 机的作用, 那么, 居里面是磁测最大深度的物理概念, 也受到冲击.

在中国布格重力异常图上(图 1), 可以明显地看到横向展布的梯级带有天山-阴山-燕山、 昆仑-秦岭和南岭, 作纵向延伸的梯级带则是鄂尔多斯与四川东侧的太行-雪峰山及其西侧的 贺兰-龙门山, 而阿尔金与祁连山梯级带围成一个顶点向上的三角形, 松潘地区受周围梯级带 包围呈顶点向下的三角形. 它们基本上勾绘出拼合中国大陆的各个块体的轮廓. 重力异常是 岩石层地壳不同层位上质量分布不均匀性的综合反映, 它与相邻层位之间的密度差有关. 宋 仲和曾明确指出 ${ }^{[8]}$ 布格重力异常是受控于地壳厚度的. 根据布格重力异常图计算出中国莫 
霍深度分布图 ${ }^{[9]}$ 可以看出, 上述纵横梯级带不仅是块体的结合带, 而且也是明显不同地壳厚 度的分界. 例如: 郯庐断裂以东, 地壳厚度从 $32 \mathrm{~km}$ 向海降低减薄; 在郯庐与太行-雪峰之间为 $35 \sim 36 \mathrm{~km}$; 鄂尔多斯与四川则增加到 $38 \sim 43 \mathrm{~km}$; 贺兰-龙门山一线以西地壳厚度增加, 但在昆 仑-秦岭以北为 $43 \sim 58 \mathrm{~km}$, 而其南在西藏地区达到 $60 \sim 70 \mathrm{~km}$. 由此可见, 前寒武纪古陆核发 展形成的块体(华北、扬子、华南、塔里木), 在古生代期间因特提斯启闭遭受严重的挤压、改造, 新生代期间又受到太平洋板块的聚玫、俯冲作用，以致即使是同一块体，也有不同的地壳厚度.

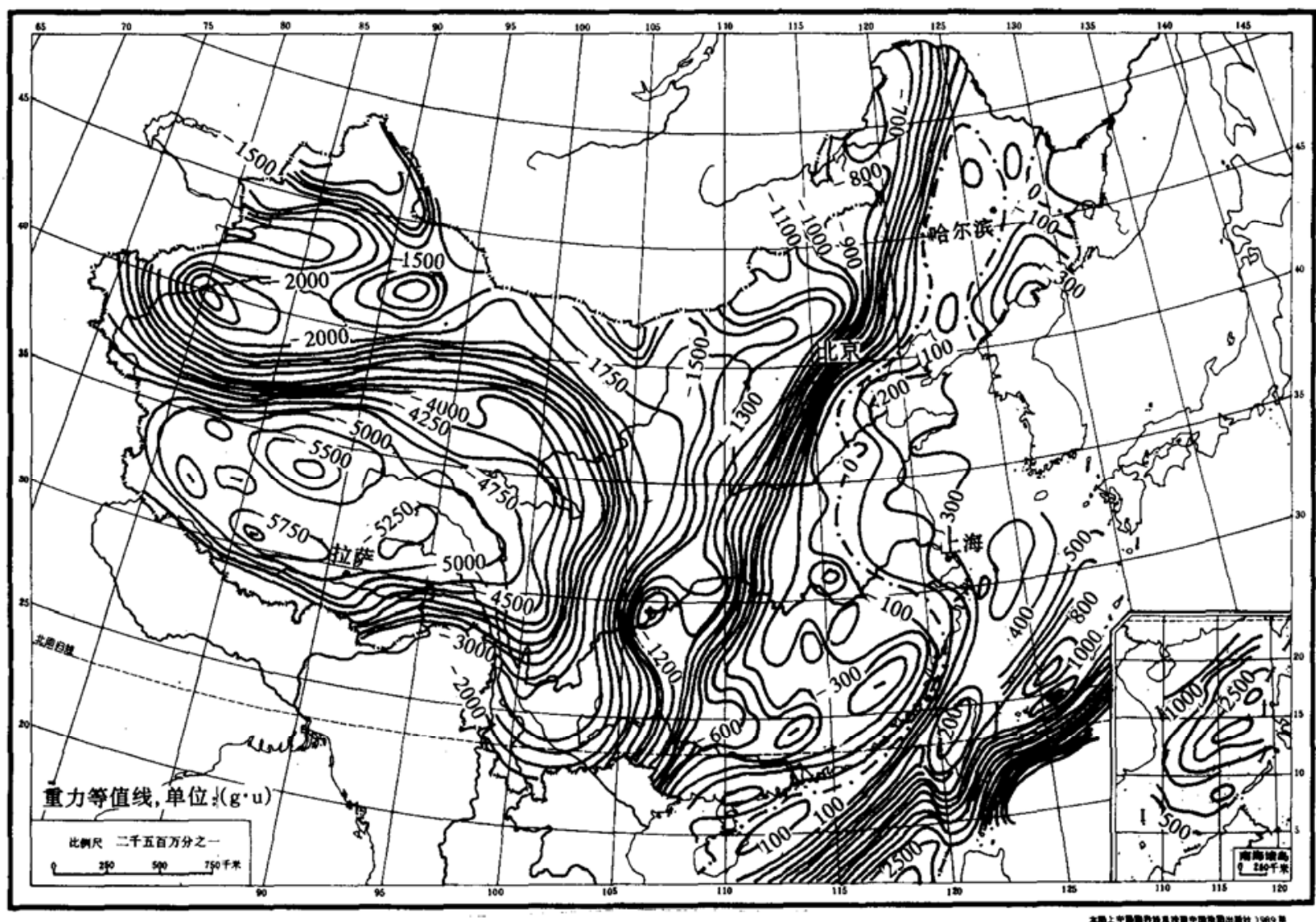

图 1 中国大陆 $1^{\circ} \times 1^{\circ}$ 布格重力异常图(据殷秀华等,有修改)

中国地震震中分布图 (图 2) 表明中国大陆地壳的活动性, 其中有些出现在块体间的结合 带上, 而更多的震中密集在帕米尔、南北带和边缘海的海沟-岛弧地带. 显然,地表出现的这些 物理现象是与中国西部特提斯的演化以及东部太平洋板块向欧亚板块俯冲有关, 而天山-燕山 一带的震中则是古生代期间西伯利亚块体向南增长, 中亚-蒙古古大洋闭合后, 西伯利亚块体 与中国大陆碰撞的痕迹. 因此, 应该努力寻求地表各种物理现象如地震、火山与热流密度等的 深部成因, 以及它们与壳幔结构之间的关系.

宋仲和等利用瑞利面波研究中国大陆及其海域的地壳-上地幔三维速度结构时指出 (1992), 横波速度分布与大陆构造单元的划分有密切关系, 它们在 $170 \mathrm{~km}$ 以上的深度内部都 存在着明显的差异. 因此, 岩石层速度结构反映出组成中国大陆的各个块体乃至次级构造单 元的形成演化过程的差别. 以岩石层速度结构来看, 其中稳定地区的主要标志是: 壳内无低速 层, 下地壳厚度大且速度高, 有壳-幔过渡层存在, 而上地幔的低速层浅, 并且有地震与火山活 


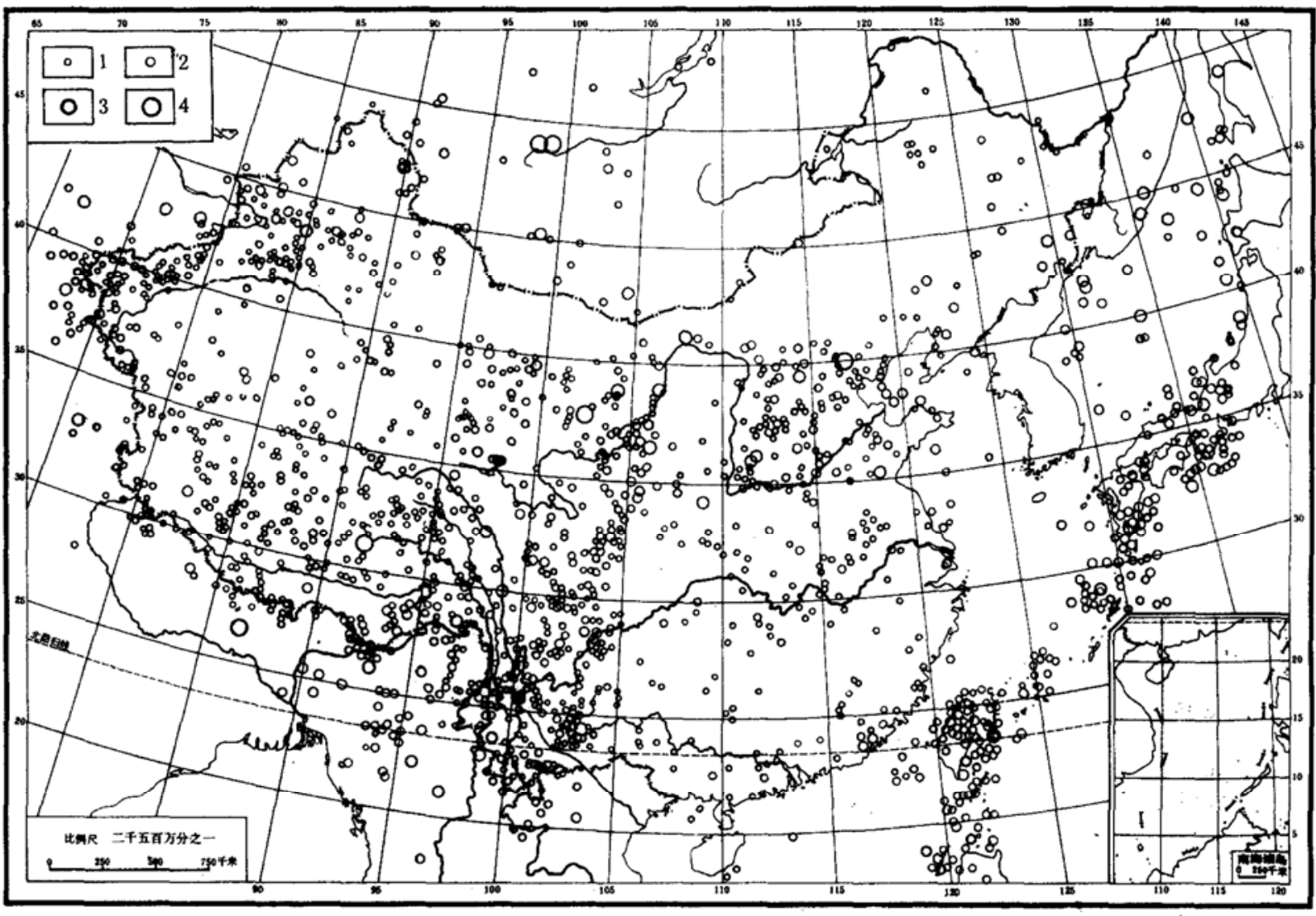

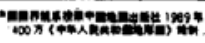

图 2 中国大陆及邻域历史地震震中分布 $\left(M s>4 \frac{3}{4}\right)$ (据国家地震局分析预报中心, 有修改)

$$
1-4 \frac{3}{4}>\mathrm{Ms}<5 ; 2-\mathrm{Ms}=5 \sim 5.9 ; 3-\mathrm{Ms}=6 \sim 6.9 ; 4-\mathrm{Ms}=7 \sim 7.9
$$

动. 根据这些特征标志分析中国大陆横波速度分布纵剖面图 (图 3) 可以看出, 在横向上有天 山-阴山-燕山、昆仑-秦岭-大别和南岭; 在纵向上有太行-雪峰和南北带. 它们勾绘出中国大陆 各块体如华北、扬子、华南和塔里木的轮廓, 表现出这些块体与不同时期结合、拼接到一起的形 迹, 具有构造活动边缘褶皱带的特点, 不仅有多种复杂开合的运动形式, 而且有多期断裂和岩 浆活动. 还可以看出, 由阿尔金和祁连山包围的柴达木盆地与松潘-甘孜地区, 呈现出顶端分 别指向南北的两个三角形, 它们在印支期以后受到青藏高原的强烈挤压, 不仅地壳结构有明显 差异, 而且深大断裂广布, 岩浆和变质作用发育, 性质十分特殊. 此外, 太行-雪峰一线是重力 梯级带, 也是地壳有差异的明显界线. 此带以东, 包括海域, 沉积盆地基本上处于拉张状态. 这是晚燕山-早喜山期以来太平洋(菲律宾)板块向欧亚板块聚玫、俯冲, 板内拉张的滨太平洋 域. 南北带以西, 在中生代时期受到特提斯海启闭以及冈瓦纳大陆裂解出来的差塘、冈底斯和 印度块体的镶嵌拼接, 而处于挤压状态, 属特提斯域. 这样, 在太行-雪峰与南北带之间, 鄂尔 多斯与四川则先后处于两大构造域作用的夹持之下, 具有过渡的剪切性质.

刘福田等 ${ }^{[10]}$ 利用中国地震台网层析成像, 重建了中国大陆及其临近地区的三维速度图 象, 揭示了地壳与上地幔存在着明显的速度横向不均匀性. 分析此不均匀性可以看出, 地质构 造特征的相关性可以追踪到 $110 \sim 220 \mathrm{~km}$, 与宋仲和利用横波速度给出的相关深度相当. 如 
$N$ (格号)

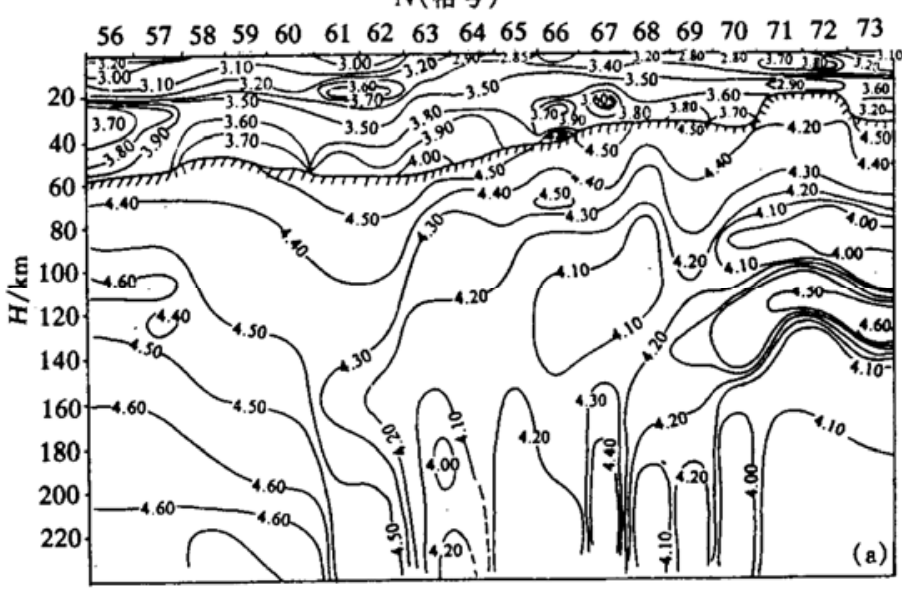

$N($ 格号)

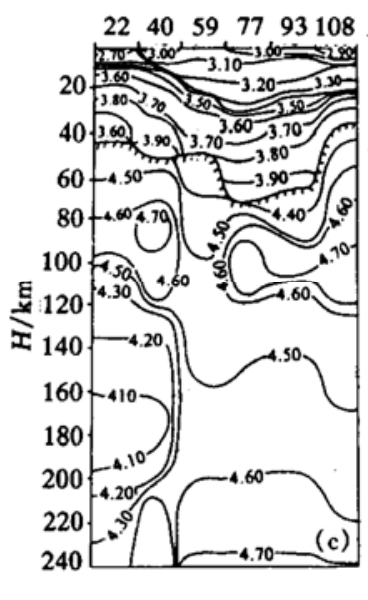

$N($ 格号)

$N($ 格号)

93949596979899100101102103104105106
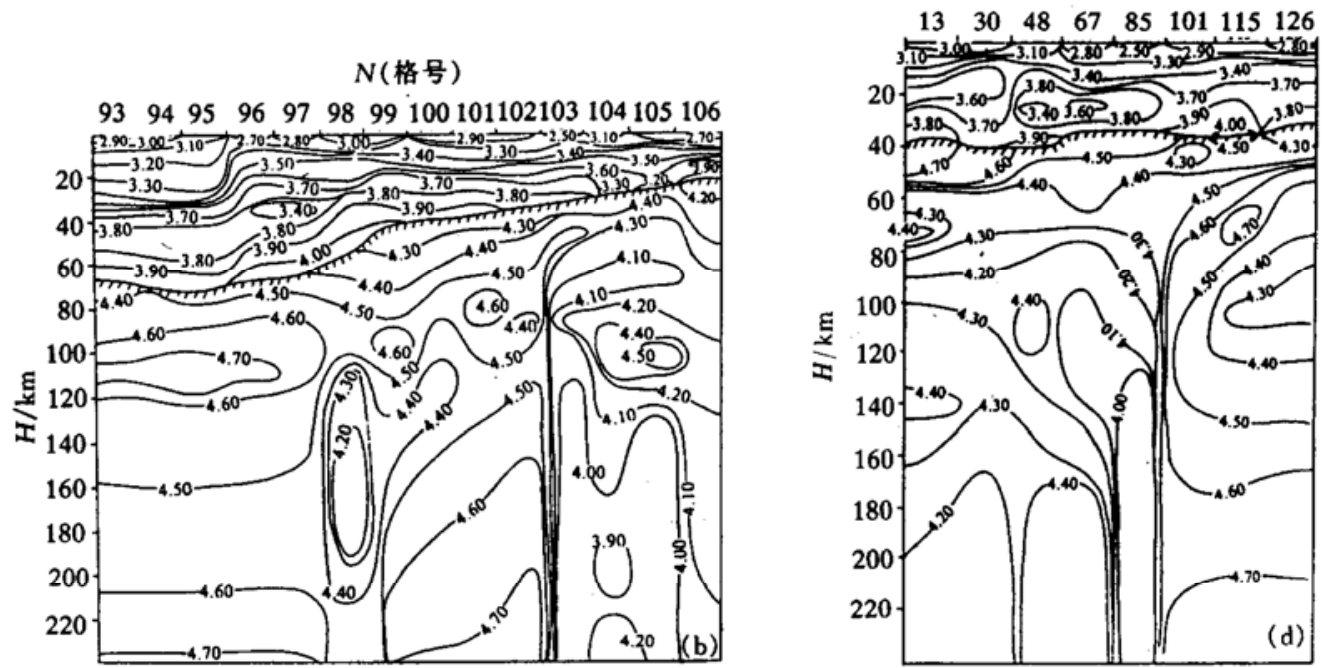

图 $3 \mathrm{~S}$ 波速度分布纵剖面图(据宋仲和等)

(a) $36 \sim 40^{\circ} \mathrm{N}$, 自西向东包括塔里木盆地西端, 其主体 $(58,59$ 格)、东昆仑 $(61,62$ 格)、祁连 (63 格) 槢鲏系、滒尔多 斯(65 格)、山西隆起 (66 格)、华北平原 (67 格)、渤海(68 格)、黄海(69 格)及朝鲜半舟 (70 格)、日本海南部 $(71,72$ 格); (b) $28-32^{\circ} \mathrm{N}$, 包括青藏高原南部( $93 \sim 96$ 格)、南北带中南部 (97, 98 格)、扬子块体( $99 \sim 102$ 格)、东海陆架 （103 106 格 ); (c)24 44 $\mathrm{N}, \operatorname{arctg}\left(\frac{1}{4}\right)$ 方向、包括印支板块恒河流域(108 格)、青藏高原西部(93,77 格)、塔里 木盆地 (59 格)、天山(40 格)、准喝尔盆地 (22 格); (d)大兴安岭西部 $(13,30$ 格)、内蒙暞皱系东端及燕山地区 (48

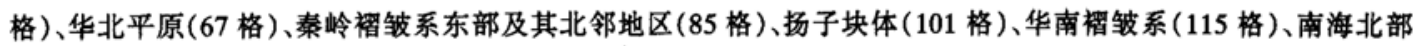
及相邻华南槢级系(126 格)

果取 $45 \mathrm{~km}$ 作为中国大陆地壳的平均厚度, 那么, 在莫霍面的上方 $(45 \mathrm{~km})$ 的图象中, 小于 45 $\mathrm{km}$ 的地壳厚度表现了正异常; 在莫霍面的下方 (45 km 以上) 的图象中, 大于 $45 \mathrm{~km}$ 的地壳厚 度表现为负异常. 这样, 中国大陆的地壳结构可以三分为: (1) 东部正异常区, 其界线在太行雪峰一线; (2)西部负异常区, 其界线相当于南北带; (3)中部正负相间的过渡区, 相当于鄂尔多 斯和四川; 但在东西分带的基础上, 又有南北分块的特点. $110 \mathrm{~km}$ 深度的层析成像切面给出 软流层的展布, 表明软流层在中国大陆普遍为低速, 只有喜马拉雅为高速区, 其他如塔里木、鄂 
尔多斯、四川与东海也有高速区的表现, 但范围小而零星. 进一步分析各特征深度上的水平切 片并与纵剖面相结合, 将可以深入讨论各块体的演化及相邻块体之间的关系. 如果能对我国 已完成的 11 条 GGT 断面进行统一的处理与解释, 必将更合理地认识中国大地构造及其演化.

\section{3 几点基本认识}

综上所述, 在板块大地构造理论的指导下, 定性分析各种地球物理场资料, 从地壳上地幔 结构与状态, 对中国大地构造宏观格架取得了 “三横, 两坚, 两个三角” 的基本认识. “三横”指 的是天山-燕山、昆仑-秦岭-大别和南岭三条基本上作东西向展布的褶皱带; “两竖” 是指太行雪峰和贺兰-龙门两条梯级带, 基本上作南北延伸; 两个 “三角”指的是阿尔金-祁连山与松潘-甘 孜两个地区, 它们都以东昆仑-秦岭为底线而顶点分别指向北和南.

这个宏观格架既反映了拼合成中国大陆的各个块体(华北、扬子、华南和塔里木)之间的结 合带, 又给出了印支运动以来中国西部受特提斯海启闭作用而具有挤压性质的特提斯域, 晚燕 山期以来中国东部受太平洋板块聚玫与菲律宾板块俯冲作用而呈拉张, 沉降性质的滨太平洋 域, 以及太行-雪峰与贺兰-龙门之间的过渡带. 因此, 这个宏观格架可以作为认识中国地质构 造环境的基础.

应该说明, “三横, 两坚, 两个三角”既是块体之间的结合带, 具有褶皱造山带或深大断裂的 活动性, 又往往与岩浆、变质作用联系起来, 从而表明这里有深部通道, 可以为金属矿提供物质 来源, 在适当的成矿与控矿条件下,应该而且可以找到金属矿床. 事实上,这些结合带与矿产 资源的关系十分密切, 我国许多大型特大型金属矿床都位于这些结合带的附近. 此外, 在上述 结合带之间有沉积盆地分布, 而每个沉积盆地的形成与演化都受到其周边结合带的制约, 乃至 会形成不同时期的盆地原型, 将它们看成一个地球动力学系统, 分析其环境、作用与其对油气 生成、聚集和运移的响应, 就可以进行整体的动态数值模拟, 评价其资源量并指导勘探.

致谢 本工作为国家“攀登”计划资助项目。

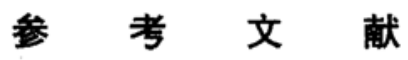

1 李四光原著. 中国地质学. 张文佑编译. 北京: 正风出版社, 1953

2 黄汲清. 中国大地构造之基本轮廊. 地质学报, 1977, 51(2):117 135

3 张文佑. 中国断裂构造体系的发展. 地质科学, 1977, 12(3):197 280

4 李春煜. 对亚洲地质构发展的新认识. 见: 中国及邻区大地构造论文集. 北京: 地质出版社, 1981. 1 21

5 王鸿祯. 中国地壳构造发展的主要阶段. 地球科学, 1982,7(3):155 173

6 刘光鼎主编. 中国海及其邻域地质地球物理系列图. 北京: 地质出版社, 1989

7 朱 夏. 活动论构造历史观. 石油实验地质, 1991, 13(3):201 209

8 Song Zhonghe, An Changqing, Chen Guoying et al. 3D S-wave velocity structure of crust and upper mantle. Science in China, Ser B, 1994, 37(1): 104 116

9 王谦身. 亚洲大陆地壳厚度分布轮麻及地壳构造特征的一些探讨. 构造地质论丛, 1985, (4): 13 23

10 刘福田, 曲克信, 吴华等. 地震层析成像. 地球物理学报, 1989, 32: 281 291

（1996-03-12 收稿, 1996-09-03 收修改稿） 